\title{
FORMAÇÃO DE MULTIPLICADORES EM SAÚDE PÚBLICA VETERINÁRIA POR MEIO DE PALESTRAS PARA PROFESSORES DOS ANOS INICIAIS DO ENSINO PÚBLICO NA CIDADE DE JATAÍ-GO, BRASIL
}

(TRAINING OF MULTIPLIERS IN VETERINARY PUBLIC HEALTH BY LECTURES TO TEACHERS OF MUNICIPAL SCHOOLS OF THE INITIAL SERIES OF PUBLIC EDUCATION IN JATAÍ-GO, $B R A Z I L)$

\section{F. FERREIRA ${ }^{1}$, A. C. BERNARDO ${ }^{1}$, G. S. FERREIRA ${ }^{2}$, E. M. N. PAULA ${ }^{2}$, D. B. SOUSA ${ }^{3}$, R. B. MEIRELLES-BARTOLI ${ }^{3 *}$}

Zoonoses são doenças transmissíveis entre homens e animais, incluindo animais invertebrados que provocam grandes prejuízos à saúde. Raiva, leptospirose, leishmaniose e toxoplasmose são enfermidades graves que merecem destaque e podem ser evitadas mediante cuidados simples que parte da população não conhece. Sensibilizar professores do ensino fundamental para a importância dessas informações é o primeiro passo para semear entre crianças e comunidade conhecimentos que servirão de base para uma relação saudável e segura entre animais e seres humanos. Objetivou-se difundir informações para professores dos anos iniciais do ensino fundamental, sobre a forma de transmissão e controle das principais zoonoses e, os principais aspectos sobre guarda responsável dos animais. Foi desenvolvida uma palestra com as principais informações sobre raiva, leptospirose, leishmaniose e toxoplasmose. As palestras para os professores foram ministradas por Médicos Veterinários do curso de Residência Multidisciplinar em Saúde - Medicina Veterinária da Universidade Federal de Goiás, Campus Jataí. Foram realizadas no ambiente escolar, totalizando 21 escolas públicas com duração aproximada de 50 minutos cada, durante o mês de março de 2013. Durante as palestras ficou evidente que a maioria dos professores não tinha conhecimento básico sobre o assunto abordado. Apesar disso, se mostraram interessados pelo tema e manifestaram desejo em compartilhar esse conhecimento com seus alunos e comunidade. Dúvidas relacionadas as zoonoses foram esclarecidas e panfletos informativos disponibilizados aos docentes. Conclui-se que o conhecimento sobre zoonoses e o impacto que podem causar à saúde pública ainda é muito escasso e a melhor forma de difundir essas informações é por meio da escola. Nesse sentido ter consciência dos aspectos básicos de guarda responsável dos animais se torna uma arma adjuvante no controle de tais enfermidades. Capacitar os professores é importante para alcançarmos o objetivo de levar o conhecimento às crianças e, consequentemente, às suas famílias e a comunidade.

\footnotetext{
${ }^{1}$ Residentes do Programa de Residência Multidisciplinar em Saúde - Medicina Veterinária da Universidade Federal de Goiás - Campus Jataí.

${ }^{2}$ Alunos do Curso de Medicina Veterinária da Universidade Federal de Goiás, Campus Jataí.

${ }^{3}$ Docentes do Curso de Medicina Veterinária da Universidade Federal de Goiás/Campus Jataí, Unidade Jatobá, Laboratório de Sanidade Animal. ${ }^{3 *}$ E-mail: raphaellabrasil@hotmail.com
} 